\title{
Seed coating with inocula of arbuscular mycorrhizal fungi and plant growth promoting rhizobacteria for nutritional enhancement of maize under different fertilisation regimes
}

\author{
Inês Rochaa, Ying Maa, Maria F. Carvalhob ${ }^{b}$ Catarina Magalhães ${ }^{b}$, Martina Janouškovác, \\ Miroslav Vosátkac, Helena Freitas ${ }^{a}$ and Rui S. Oliveira ${ }^{a, d}$ \\ ${ }^{a}$ Centre for Functional Ecology - Science for People \& the Planet, Department of Life Sciences, University of \\ Coimbra, Coimbra, Portugal; ${ }^{\mathrm{b} C I I M A R}$ - Interdisciplinary Centre of Marine and Environmental Research, University \\ of Porto, Matosinhos, Portugal; Institute of Botany, Academy of Sciences of the Czech Republic, Prühonice, Czech \\ Republic; ${ }^{d}$ Department of Environmental Health, Research Centre on Health and Environment, School of Health, \\ Polytechnic Institute of Porto, Porto, Portugal
}

\begin{abstract}
Arbuscular mycorrhizal (AM) fungi and plant growth-promoting rhizobacteria, responsible for enhancing plant nutrition, vigour and growth, may be used to reduce dosages of chemical fertilisers. Technologies that allow an economically viable and efficient application of these beneficial microbes in large scale agriculture must be studied. Seed coating is a potential delivery system for efficiently introducing minor amounts of bioinoculants. Despite the dramatic reduction on inoculum dose per plant, inoculation of AM fungi via seed coating was as effective as conventional soil inoculation. Fertilisation and inoculation had a significant impact on maize shoots nutrient concentrations. Different fertilisation regimes did not influence mycorrhizal colonisation. Plants without fertilisation and singly inoculated with $R$. irregularis showed shoot nutrient concentration increments of $110,93,88$ and $175 \%$ for nitrogen, phosphorus, potassium and zinc, respectively, comparing with non-inoculated controls. Plants singly inoculated with $P$. fluorescens via seed coating under full fertilisation, presented enhancements of 100,75 and $141 \%$ for magnesium, zinc and manganese, respectively, comparing with non-inoculated controls. Seed coating is a promising tool for delivering microbial inoculants into the soil, while promoting sustainable production of maize. This technology is particularly pertinent in low input agriculture, with potential environmental profits and food quality improvements.
\end{abstract}

KEYWORDS Plant growth promoting microorganisms; biofertilisers; soil inoculation; fertility; sustainable agriculture

A new route on agricultural practices is required to ease the pressure on the environment and human health (Adesemoye et al. 2009; Malusá et al. 2012). In order to maintain productivity and reduce the input of agrochemicals, the exploitation of plant beneficial microbes, such as arbuscular mycorrhizal (AM) fungi and plant growth-promoting rhizobacteria (PGPR) is of great potential (Kumar et al. 2007; Walker et al. 2011; Couillerot et al. 2013).

The roles of AM fungi in agriculture are widely recognised, as they have the capacity to improve plant fitness by enhancing uptake of nutrients and water, protecting plants against biotic and abiotic stresses and improving soil quality and structure (Mäder et al. 2011; Njeru et al. 2015; 
Oliveira et al. 2017a, 2017b). On the other hand, PGPR are responsible for promoting growth and plant protection through mechanisms such as production of siderophores and phytohormones, nitrogen fixation, reduction of ethylene levels, solubilisation of nutrients and induction of pathogen resistance (Walker et al. 2011; Bhattacharyya and Jha 2012; Nadeem et al. 2014). Among all the mechanisms they may also stimulate the development of mycorrhiza. Some mycorrhiza helper bacteria, such as Pseudomonas fluorescens F113 can facilitate root colonisation by AM fungi, and at the same time display properties of plant growth promoting bacteria (Couillerot et al. 2013).

In agricultural practice only 10 to $40 \%$ of the total applied chemical fertilisers are taken by the plants, the remaining is lost by a variety of mechanisms or processes (Bhardwaj et al. 2014). PGPR and AM fungi can greatly improve nutrient use efficiency, leading to a reduced need for chemical fertilisers (Adesemoye et al. 2009; Bhardwaj et al. 2014; Oliveira et al. 2016a, 2016b).

With over 1 billion ton harvested worldwide in 2013, maize (Zea mays L.) is the world's most cultivated cereal crop, with indubitable economic and nutritional value (Berta et al. 2014; Zerbe 2015). To meet the growing demand for this cereal and to satisfy the need for a more sustainable agriculture with lower agrochemical inputs, AM fungi and PGPR stand as promising tools (Malusá et al. 2016). Recent studies demonstrated the efficiency of these beneficial microbes in promoting maize growth and yield in field experiments (Adesemoye et al. 2008; Jarak et al. 2012; Krey et al. 2013; Sangeetha et al. 2013; Berta et al. 2014) and in greenhouse trials (Wu et al. 2005; Couillerot et al. 2013). Despite these promising results, the application of both AM fungi and PGPR by broadcasting inocula in open agricultural fields is not economically feasible, since non targeted spreading of inoculum over large areas results in high cost per plant (Vosátka et al. 2012; Oliveira et al. 2016b). In order to use minor amounts of inoculum, seed coating, a technique in which a certain active compound is adhered around the seed, is here proposed as an inoculation mechanism for maize seeds (Ehsanfar and Modarres-Sanavy 2004; Colla et al. 2015; Oliveira et al. 2016b).

The aims of the present study were to (i) assess the effectiveness of seed coating as a delivery system of inocula of AM fungi and PGPR and (ii) evaluate whether the application of microbial inoculants via seed coating could minimise the input of chemical fertiliser in maize production.

\section{Materials and methods}

\section{Soil and plant material}

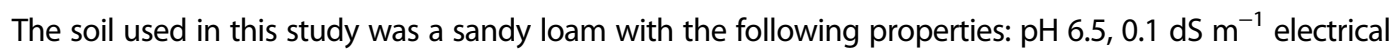
conductivity, $1.2 \%$ organic matter, $3.8 \mathrm{~g} \mathrm{~kg}^{-1}$ total nitrogen (N), $48.8 \mathrm{mg} \mathrm{kg}^{-1}$ extractable phosphorus (P), $4.3 \mathrm{~g} \mathrm{~kg}^{-1}$ potassium (K), $1.6 \mathrm{~g} \mathrm{~kg}^{-1}$ calcium (Ca), $66 \mathrm{mg} \mathrm{kg}^{-1}$ magnesium (Mg) and $147 \mathrm{mg} \mathrm{kg}^{-1}$ sodium (Na). The soil, collected from an organic farm in northern Portugal, was sieved $(4 \mathrm{~mm})$ and autoclaved twice at $121^{\circ} \mathrm{C}$ for $25 \mathrm{~min}$. Maize (Zea mays L.) seeds (ACC No06694, free pollination) were obtained from Banco Português de Germoplasma Vegetal, Instituto Nacional de Investigação Agrária e Veterinária.

\section{Inoculum preparation and seed coating}

The AM fungus used was Rhizophagus irregularis BEG140 grown for 8 months in a multispore pot culture containing a 1:1 (v/v) mixture of zeolite and expanded clay with Trifolium pratense $\mathrm{L}$. as host plant. For the seed coating procedure, the $R$. irregularis inoculum was sieved through a $500 \mu \mathrm{m}$ mesh and mixed with silicon dioxide $(1: 1 \mathrm{w} / \mathrm{w})$, which served as coating material (the inoculum-coating material mixture was provided by Symbiom Ltd., Czech Republic). For plants where the seeds were not coated, the same AM fungal inoculum was used without sieving.

Pseudomonas fluorescens F113, a PGPR isolated from sugar beet rhizosphere by Fenton et al. (1992), was purchased from the International Center for Microbial Resources from the Bacteria Associated with Plants strain collection (CFBP 5935) in France (http://www6.inra.fr/cirm_eng/CFBPPlant-Associated-Bacteria). To obtain $P$. fluorescens inocula, bacteria cells were grown on Luria 
Bertani (LB) medium supplemented with $0.25 \mathrm{~g} \mathrm{I}^{-1} \mathrm{MgSO}_{4} \cdot 7 \mathrm{H}_{2} \mathrm{O}$ for $8 \mathrm{~h}$ at $30^{\circ} \mathrm{C}$ and $200 \mathrm{rpm}$, according to the procedures from Couillerot et al. (2013). For the seed coating, P. fluorescens grown in LB media was centrifuged at $7000 \mathrm{rpm}$ for $10 \mathrm{~min}$ and resuspended in $10 \mathrm{mM} \mathrm{MgSO}{ }_{4} \cdot 7 \mathrm{H}_{2} \mathrm{O}$ with $2 \%(\mathrm{w} / \mathrm{w})$ glycerol, added as a protective agent to the cell suspension to minimise the loss of cell viability during the coating process, and mixed with the coating material (1:1 v/w). Both fungus and bacterium were also coated together using the same procedure and proportions $(1: 1: 1 \mathrm{w} / \mathrm{v} / \mathrm{w})$ as aforesaid. Maize seeds were coated by gradually adding the inoculum-coating mixture and air dried at $22-23^{\circ} \mathrm{C}$ for $72 \mathrm{~h}$ according to the pan coating method (Scott et al. 1991) as described by Oliveira et al. (2016b). Non-inoculated control seeds were coated only with silicon dioxide.

\section{Experimental design}

This study was divided in two experiments (A and B), which were performed simultaneously. Both trials were conducted in a greenhouse with a temperature and relative humidity ranging from 14 to $42^{\circ} \mathrm{C}$ (average 20 to $30^{\circ} \mathrm{C}$ ) and from 55 to $85 \%$, respectively, and with an average photoperiod of $12 \mathrm{~h}$. Pots of $3 \mathrm{~L}$ were disposed in a fully randomised scheme for both experiments and in order to minimise differences due to their location in the greenhouse, their positions were periodically swapped.

Experiment $A$ aimed at comparing conventional soil inoculation with seed coating inoculation and encompassed seven treatments: (i) non-inoculated controls (C), (ii) $R$. irregularis conventionally inoculated in the soil (Rlsoil), (iii) $R$. irregularis inoculated through seed coating (Rlcoat), (iv) $P$. fluorescens conventionally inoculated in the soil (PFsoil), (v) P. fluorescens inoculated through seed coating (PFcoat), (vi) a consortium of $R$. irregularis and $P$. fluorescens conventionally inoculated in the soil (RI+PFsoil), and (vii) a consortium of $R$. irregularis and $P$. fluorescens inoculated through seed coating (RI+PFcoat). Plants that were treated by conventional soil inoculation with $R$. irregularis (Rlsoil), received $12 \mathrm{~g}$ of non-sieved inoculum placed $2 \mathrm{~cm}$ below one uncoated seed, which corresponded to $4860 \mathrm{AM}$ fungal propagules (viable inoculum) per plant, estimated by the most probable number method (MPN) (Porter 1979). Pots from the Rlcoat treatments received one maize seed coated with R. irregularis, which corresponded to 273 AM fungal propagules per plant, estimated by the MPN method after the coating procedure. For the treatment PFsoil, $1 \mathrm{ml}$ of bacterial suspension with a concentration of $10^{7}$ colony-forming unit (CFU) $\mathrm{ml}^{-1}$ was pipetted onto each pot that received one uncoated maize seed, while for the coated seed treatment (PFcoat), the same CFU concentration was mixed with the coating material according to the aforementioned procedure. After coating, a final bacterial concentration of $10^{5} \mathrm{CFU}$ per coated seed was obtained. The CFU was estimated by placing one coated seed in $1 \mathrm{ml}$ of ringer solution followed by serial dilutions and plate count method. For the treatment RI+PFsoil, each pot received one uncoated seed plus $12 \mathrm{~g}$ of fungal inoculum and $1 \mathrm{ml}$ bacterial inoculum as described above. Pots of non-inoculated control plants received one $Z$. mays seed coated only with silicon dioxide. Each treatment combination was replicated 8 times. Each plant received $25 \mathrm{ml}$ of full strength Hoagland solution (composition described below) with $20 \%$ of $\mathrm{P}$ twice a week.

Experiment $B$ aimed at evaluating the growth and nutritional status of maize inoculated with AM fungi and PGPR via seed coating, under 3 levels of fertilisation (no fertilisation, reduced fertilisation and full fertilisation). Experimental pots were arranged in a $4 \times 3$ factorial design, where the first factor was inoculation [non-inoculated controls (C), $R$. irregularis inoculated through seed coating (Rlcoat), P. fluorescens inoculated through seed coating (PFcoat) and a consortium of $R$. irregularis and $P$. fluorescens inoculated through seed coating (Rl+PFcoat)] and the second was fertilisation [no fertilisation (F0), $80 \%$ strength Hoagland solution with $20 \%$ of P (F1) and full strength Hoagland solution (F2)]. Fertilised plants received $25 \mathrm{ml}$ of the corresponding Hoagland solution per pot twice per week and non-fertilised plants received $25 \mathrm{ml}$ deionised water. The composition of the full strength Hoagland solution was: $224 \mathrm{mg} \mathrm{I}^{-1} \mathrm{KNO}_{3}, 235 \mathrm{mg} \mathrm{I}^{-1} \mathrm{Ca}\left(\mathrm{NO}_{3}\right) \cdot 4 \mathrm{H}_{2} \mathrm{O}, 160 \mathrm{mg} \mathrm{I}^{-1}$ $\mathrm{NH}_{4} \mathrm{H}_{2} \mathrm{PO}_{4}, 62 \mathrm{mg} \mathrm{l}^{-1} \mathrm{MgSO}_{4} \cdot 7 \mathrm{H}_{2} \mathrm{O}, 1.77 \mathrm{mg} \mathrm{l}{ }^{-1} \mathrm{KCl}, 0.27 \mathrm{mg} \mathrm{l}^{-1} \mathrm{H}_{3} \mathrm{BO}_{3}, 0.11 \mathrm{mg} \mathrm{l}{ }^{-1} \mathrm{MnSO}_{4}$. $\mathrm{H}_{2} \mathrm{O}, 0.13 \mathrm{mg} \mathrm{I}^{-1} \mathrm{ZnSO}_{4} \cdot 7 \mathrm{H}_{2} \mathrm{O}, 0.03 \mathrm{mg} \mathrm{I}^{-1} \mathrm{CuSO}_{4} \cdot 5 \mathrm{H}_{2} \mathrm{O}, 0.05 \mathrm{mg} \mathrm{l}^{-1} \mathrm{H}_{2} \mathrm{MoO}_{4}\left(85 \% \mathrm{MoO}_{3}\right), 3 \mathrm{mg} \mathrm{I}^{-1}$ 
NaFeEDTA (10\% Fe) (Taiz and Zeigher 2002). The reductions of $80 \%$ strength and $20 \%$ of $P$ were made to the full strength solution. The coating procedure, amounts and concentrations of inocula used in experiment $B$ were the same as those in experiment A. Each treatment combination was replicated 8 times.

\section{AM fungal analysis}

In both experiments the presence of $R$. irregularis in the roots of maize was assessed by microscopic methods. According to a modified Phillips and Hayman (1970) protocol (Oliveira et al. 2005), the roots of maize were cut into $1-\mathrm{cm}$ pieces and stained with trypan blue for the assessment of the percentage of root length colonised (RLC) and abundance of arbuscules and vesicles. The RLC by AM fungi in the mycorrhizal root segments was evaluated by the grid-line intersect method (Giovannetti and Mosse 1980) under a stereomicroscope (Leica EZ4 HD, Germany). Arbuscule and vesicle abundances were examined under a compound microscope (Leica DM 5000-D, Germany) $(\times 100-400)$ as described by Troulevout et al. (1986) and the percentages determined with the software Mycocalc (http://www.dijon.inra.fr/mychintec/Mycocalc-prg/download.html).

\section{PGPR analysis}

After 70 days of growth, $1 \mathrm{~g}$ of maize roots and adhering soil was sampled and transferred into a $50 \mathrm{ml}$ tube and flash-frozen in liquid $\mathrm{N}$. The extraction of DNA from $P$. fluorescens present in the rhizosphere of maize was performed as described by Couillerot et al. (2010). The samples were homogenised using Precellys24 (Bertin instruments, France) and 250-300 mg used for DNA extraction, using the FastDNA ${ }^{\oplus}$ SPIN $^{\circledR}$ kit for soil (MPBiomedicals, CA, USA). The DNA quantification was made using Qubit fluorometric quantitation system (Life Technologies, Carlsbad, CA, USA) according to the manufacturer's recommendations. The primers used, F113_1_for (CAAGAAAGGTGAGCCGAGAC) and F113_1_rev (CGACAACCAGCACTTGAGAA) were designed and previously tested, with attainment, for $P$. fluorescens by Von Felten et al. (2010). The quantification by real-time polymerase chain reaction (PCR) was based on the methodology described by Walker et al. (2011). A Step One Plus Real-time PCR system (Applied Biosystems, Canada) was used with the following conditions: $20 \mu$ reaction volume with $0.5 \mu \mathrm{M}$ of each primer, $2 \mu \mathrm{l}$ of template DNA and $10 \mu \mathrm{l}$ Fast Sybr Green mix (Applied Biosystems, Canada). The two-step cycling program included an initial pre-incubation of $20 \mathrm{~s}$ at $95^{\circ} \mathrm{C}$ followed by 40 cycles of $95^{\circ} \mathrm{C}$ for $3 \mathrm{~s}$ and $60^{\circ} \mathrm{C}$ for $30 \mathrm{~s}$.

\section{Plant analysis}

In both experiments ( $A$ and $B$ ) plants were harvested after a growth period of 70 days, the root system separated from the shoot and washed to remove adhered soil. In experiment $B$, shoots were dried at $70^{\circ} \mathrm{C}$ for $48 \mathrm{~h}$ and weighed. After drying, stems were grained and digested according to the European Standard EN 13805 (2014). Total P, K, Ca, Mg, sulfur (S), iron (Fe), manganese $(\mathrm{Mn})$ and zinc $(\mathrm{Zn})$ were determined by inductively coupled plasma optical emission spectrometry (ICP-OES; GBC Quantima, Australia). Operating conditions for ICP-OES determinations were as follows: RF power $-1000 \mathrm{~W}, 15.01 \mathrm{~min}^{-1}$ plasma gas flow rate, $1.2 \mathrm{I} \mathrm{min} \mathrm{m}^{-1}$

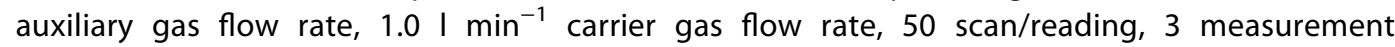
replicates and dual detector. Total $\mathrm{N}$ was determined with a segmented flow analyser (Skalar Inc. SanPlus, The Netherlands). 


\section{Statistical analysis}

Normality and homogeneity of variances were confirmed and data analysed using one-way and two-way analysis of variance (ANOVA) for each dependent variable (plant and fungal parameters) versus the independent variables (inoculation, in experiment $A$ and inoculation and fertilisation in experiment B). For experiment $B$ the main effects of the factors inoculation (C, PFcoat, Rlcoat and RI +PFcoat), fertilisation (F0, F1 and F2) and their interaction were analysed. When a significant $F$-value was obtained $(P<0.05)$, treatment means were compared using Duncan's multiple range test. Fungal parameters data were analysed without including the respective non-inoculated control treatments and the bacteria inoculated treatments. All statistical analyses were performed with the SPSS 23.0.0 software package (IBM SPSS Statistics, USA).

\section{Results}

In both experiments, coated and non-coated seeds had a germination rate of $100 \%$. After 70 days, non-inoculated plants formed no AM fungal root colonisation. In experiment $A$, all plants inoculated with AM fungi had root mycorrhizal colonisation, with values higher than $70 \%$ and presence of arbuscules and vesicles (Figure 1). The results showed no significant differences in \% RLC, arbuscule and vesicule abundances between plants conventionally inoculated in the soil with $R$. irregularis and those inoculated via seed coating, regardless of inoculation with $P$. fluorescens (Figure 1). No effect of bacterial inoculation on root colonisation by AM fungi was observed. In experiment $B$, all AM fungi inoculated plants showed root mycorrhizal colonisation, while control and bacteria inoculated treatments presented no AM fungal colonisation. Root length colonisation was higher than $60 \%$ in all treatments. The \% of RLC, arbuscule and vesicle abundances in the mycorrhizal roots of plants inoculated with $R$. irregularis, presented no significant differences across the different levels of fertilisation (Table 1). No effect of bacterial inoculation on the AM fungal root colonisation was perceived.

After the coating procedure and prior to sowing, seeds treated with $P$. fluorescens presented a concentration of $10^{5} \mathrm{CFU}$ per coated seed, yet after the 70 days of plant growth, it was not possible

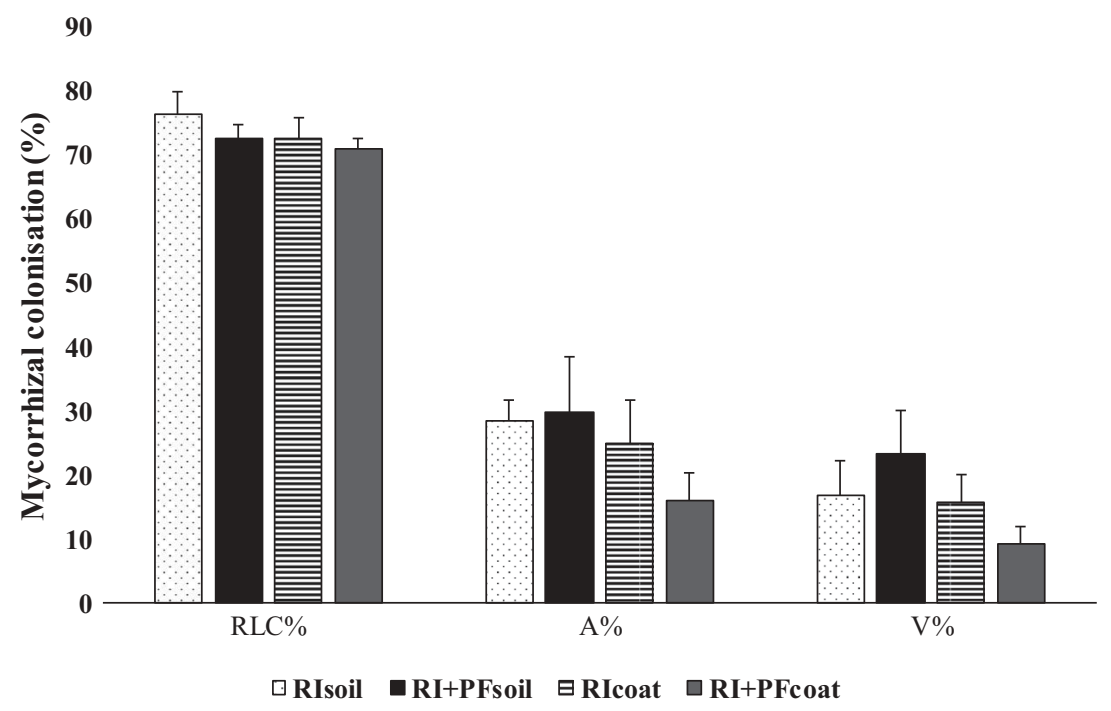

Figure 1. Experiment $A$ - Percentage root length colonised (\%RLC), arbuscule (A\%) and vesicle (V\%) abundances in the roots of Zea mays L. conventionally inoculated in the soil with Rhizophagus irregularis (RIsoil) or R. irregularis + Pseudomonas fluorescens (RI+PFsoil) or inoculated via seed coating (Rlcoat and RI+PFcoat). Values are means $\pm 1 \mathrm{SE}$. There were no significant differences according to Duncan's Multiple Range test at $P<0.05$. 
Table 1. Experiment B - Percentage of root length colonised (\%RLC), arbuscule (A\%) and vesicle (V\%) abundances of Rhizophagus irregularis (Rlcoat) and R. irregularis and Pseudomonas fluorescens consortium (RI+PFcoat) inoculated via seed coating in the roots of Zea mays L. under no fertilisation (F0), reduced fertilisation (F1) and full fertilisation (F2).

\begin{tabular}{lllrr}
\hline Inoculation & Fertilisation & RLC\% & A\% & V\% \\
\hline Rlcoat & F0 & $67.8 \pm 3.8$ & $25.9 \pm 8.6$ & $18.3 \pm 8.8$ \\
& F1 & $62.2 \pm 6.3$ & $17.7 \pm 6.3$ & $10.7 \pm 3.0$ \\
Rl+PFcoat & F2 & $69.7 \pm 6.6$ & $25.5 \pm 4.3$ & $15.1 \pm 3.1$ \\
& F0 & $64.5 \pm 1.6$ & $19.3 \pm 4.1$ & $6.3 \pm 1.6$ \\
& F1 & $76.8 \pm 1.1$ & $16.8 \pm 3.1$ & $12.4 \pm 2.0$ \\
& F2 & $62.4 \pm 5.6$ & $17.1 \pm 5.8$ & $9.5 \pm 2.8$ \\
\hline
\end{tabular}

Values are means ( $\pm 1 \mathrm{SE})$. There were no significant differences according to Duncan's Multiple Range test at $P<0.05$.

to detect the bacterial strain by the used molecular methods. Therefore, the presence of $P$. fluorescens could not be confirmed in the roots and rhizosphere of maize.

In experiment $B$, both shoot and root dry weights of maize were positively affected by the fertilisation regime. For instance, roots and shoots had higher biomass at full fertilisation and lower biomass without fertilisation, irrespective of the inoculation treatments (Figure 2 and Table 2). Inoculation had a significant impact on root biomass and no influence on shoots, being the interaction between inoculation and fertilisation only significant regarding roots (Table 2). Plants subjected to reduced fertilisation and inoculated with $R$. irregularis presented lower root biomass when compared with the remaining treatments. Overall, plants inoculated with beneficial microbes showed no growth enhancement. Both inoculation and fertilisation factors influenced the final maize shoot nutrient concentrations (Tables 3 and 4). Plants inoculated singly with $P$. fluorescens (PFCoat) increased their shoot concentration of N, K, Ca, Mg and Mn by 40, 49, 60, 100 and 141\%, respectively. Most of the increments were observed under full fertilisation regime. Treatments where only R. irregularis was added (Rlcoat), showed substantial increases in N and Zn shoot

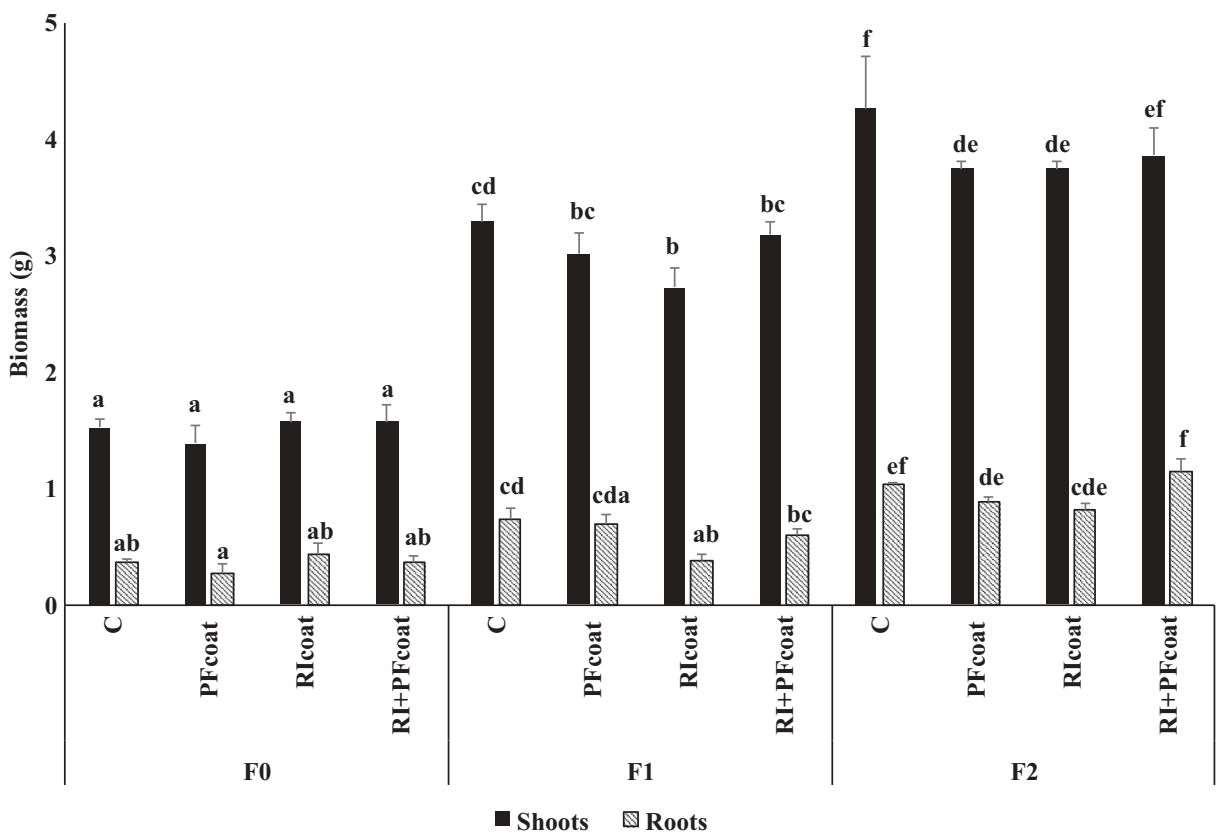

Figure 2. Experiment B - Shoot and root dry weight of Zea mays L. obtained from coated seeds non-inoculated (C), inoculated with Rhizophagus irregularis (RIcoat), Pseudomonas fluorescens (PFcoat) and a consortium of $R$. irregularis and P. fluorescens (RI + PFcoat) under no fertilisation (F0), reduced fertilisation (F1) and full fertilisation (F2). Values are means ( \pm 1 SE) followed by letters that indicate significant differences according to Duncan's Multiple Range test at $P<0.05$. 
Table 2. Experiment B - Main effects of the factors inoculation and fertilisation and two-way ANOVA F-values and significances for shoot and root biomass of Zea mays L.

\begin{tabular}{|c|c|c|c|}
\hline Main effects & & Shoot dry weight $(\mathrm{g})$ & Root dry weight $(\mathrm{g})$ \\
\hline \multirow[t]{4}{*}{ Inoculation (I) } & $\mathrm{C}$ & $2.74 \mathrm{a}$ & $0.63 \mathrm{~b}$ \\
\hline & PFcoat & $2.61 \mathrm{a}$ & $0.61 \mathrm{ab}$ \\
\hline & Rlcoat & $2.51 \mathrm{a}$ & $0.50 \mathrm{a}$ \\
\hline & $\mathrm{Rl}+\mathrm{PF}$ coat & $2.77 \mathrm{a}$ & $0.62 a b$ \\
\hline \multirow[t]{3}{*}{ Fertilisation(F) } & F0 & $1.52 \mathrm{a}$ & $0.37 \mathrm{a}$ \\
\hline & $\mathrm{F} 1$ & $3.06 \mathrm{~b}$ & $0.61 \mathrm{~b}$ \\
\hline & $\mathrm{F} 2$ & $3.88 \mathrm{c}$ & $0.95 \mathrm{c}$ \\
\hline \multicolumn{4}{|c|}{ Two-way ANOVA F-values and significances } \\
\hline Inoculation (I) & & $2.7 \mathrm{~ns}$ & $3.5^{*}$ \\
\hline Fertilisation $(\mathrm{F})$ & & $218.1^{* * *}$ & $60.2^{* * *}$ \\
\hline $\mathrm{I} \times \mathrm{F}$ & & $1.1 \mathrm{~ns}$ & $3.4^{*}$ \\
\hline
\end{tabular}

Letters indicate significant differences according to Duncan's Multiple Range test. ${ }^{*}$ and ${ }^{* * *}$, significant effect at the level of $P<0.05$ and $P<0.001$, respectively; ns, non-significant effect. $C$, non-inoculated controls; PFcoat, Pseudomonas fluorescens; Rlcoat, Rhizophagus irregularis; RI+PFcoat, consortium of $R$. irregularis and $P$. fluorescens; F0, no fertilisation; F1, reduced fertilisation; F2, full fertilisation.

concentrations under all fertilisation levels. Nevertheless, the higher values of enhancement and the number of nutrients affected by the AM fungi inoculation where obtained in the F0 and F1 fertilisation levels. In Rlcoat treatment without fertilisation (F0) N, P, K, Mg and $\mathrm{Zn}$ had increments of $110,93,88,73$ and $175 \%$, respectively. In reduced fertilisation regime (F1) the same nutrients had increases of $44,20,68,58$ and $145 \%$, respectively, while under full fertilisation (F2) only $N$ and Zn concentrations were enhanced. Plants inoculated with $R$. irregularis $+P$. fluorescens (RI+PFcoat) showed a significant enhancement of $\mathrm{N}, \mathrm{Ca}, \mathrm{Mg}$ and $\mathrm{Zn}$ shoot concentration, mainly under $\mathrm{F} 0$ and F1 fertilisation levels. It is noteworthy that in plants inoculated with AM fungi, nutrient content enhancement was higher in treatments under reduced fertilisation than in those under full fertilisation. No influence by $R$. irregularis or $P$. fluorescens was noticed in $\mathrm{S}$ and Fe shoot concentrations. The analyses of the main effects of microbial inoculation on maize shoot nutrient concentration showed significant increases in all assessed nutrients, except for $\mathrm{P}$ and $\mathrm{S}$ in PFcoat, $\mathrm{Fe}$ and $\mathrm{Mn}$ in Rlcoat and $\mathrm{K}, \mathrm{S}$ and $\mathrm{Fe}$ in RI+PFcoat (Table 4). The main effects of fertilisation only showed significant differences in $\mathrm{N}$ and $\mathrm{P}$ shoot concentrations. Higher fertilisation resulted in increased $\mathrm{N}$ and reduced $\mathrm{P}$ shoot concentration (Table 4).

\section{Discussion}

The seed coating process used in this study had no negative effect on seed germination. Previously, the same seed coating method had been used with wheat seeds by Oliveira et al. (2016b), also with a germination rate of $100 \%$. Maize and wheat seeds have different sizes and shapes, showing the applicability of this seed coating procedure to dissimilar types of seeds. Due to the relatively high cost of AM fungi inocula per plant, the application in open agricultural fields, apparently is not economically feasible (Vosátka et al. 2012). This study showed that in the case of AM fungi, the use of minor amounts of inoculum through inoculation via seed coating is possible, resulting in similar root colonisation when compared with conventional soil inoculation. Comparable results were also obtained by Oliveira et al. (2016b) with wheat seeds coated with AM fungi. With the seed coating process, inoculated bacteria can suffer a loss of viability in the seed, which consequently could have a negative effect on colonisation and persistence of bacteria in the soil (Pedrini et al. 2016). However, after the coating procedure and prior to sowing, seeds treated with $P$. fluorescens presented a concentration of $10^{5} \mathrm{CFU}$ per coated seed, which is sufficient for successful colonisation (Weller 1983; Tang et al. 1995; Landa et al. 2003). Yet, after the 70 days of plant growth, it was not possible to detect the inoculated bacterial strain in the soil samples by 


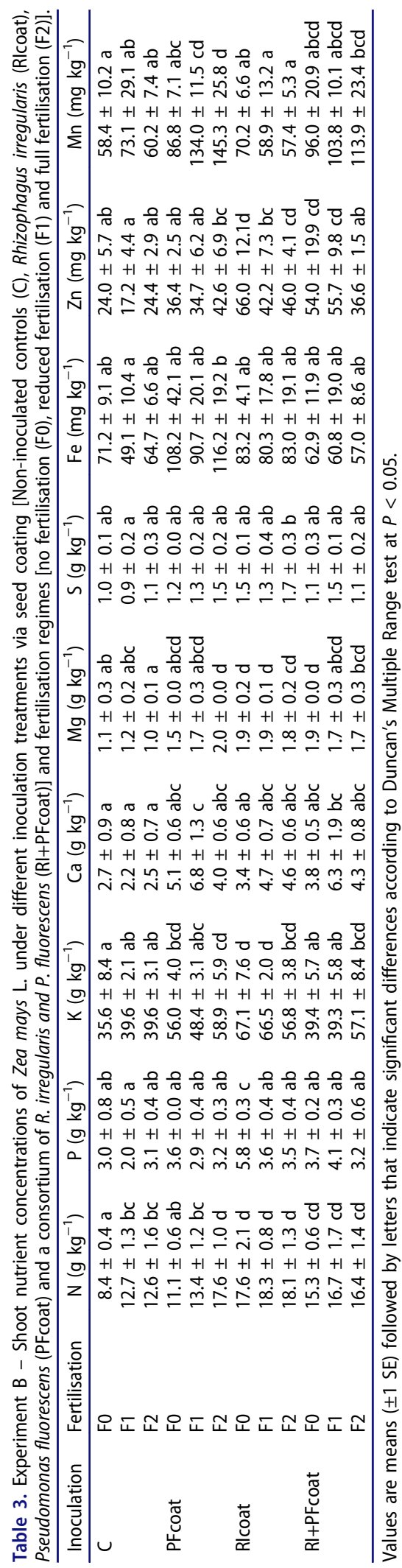




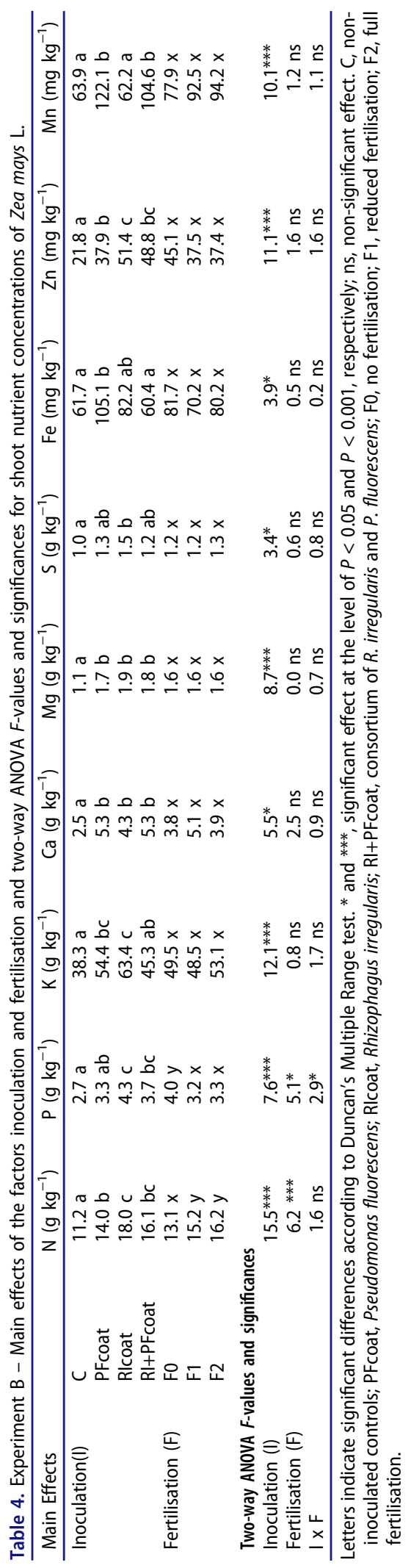


molecular methods, indicating that the concentration of $P$. fluorescens was possibly below the detection limit for the QPCR analysis. That fact might be related with the findings of Von Felton et al. (2010) who reported a decrease with time in the population density of $P$. fluorescens F113. This was also pointed out by Haas and Défago (2005), who showed that introduced PGPR can colonise plant roots initially at levels of about $10^{7}-10^{8} \mathrm{CFU} \mathrm{g^{-1 }}$ but these levels always decline in a few weeks. The persistence in the soil of introduced rhizobacteria can vary considerably from plant to plant (Landa et al. 2003). The decline can be related with several factors such as direct growth inhibition, resource competition (root exudates utilisation) or need of a wider range of resources than other bacteria (Adee et al. 1990; Farrar et al. 2014). Moreover, in experiments with wheat and maize, Rosas et al. (2009) showed that Pseudomonas aurantiaca can, in fact, decrease over time in rhizosphere soil yet, effects of the inoculated bacteria on plant growth were shown during the whole cycle of the crop. Thus, in our study, the fact that the presence of $P$. fluorescens F113 in the soil could not be confirmed after 70 days, should not lead to the conclusion that there was no bacterial effect in different phases of plant development. In future studies, it will be crucial to perform time course samplings throughout the development of the roots in order to understand the behaviour of the inoculated bacteria and also to comprehend the impact on the target plants of changes in bacterial concentrations in the roots and rhizosphere. Depending on the bacteria, the development of mycorrhiza can be negatively or positively affected. In fact, most of these interactions are competitive, but some can be beneficial to the mycorrhizal colonisation process (Garbaye 1994). Pseudomonas fluorescens are of great predisposition to benefit mycorrhiza establishment and specifically strain F113 proved to be capable of improving the formation of AM associations, as previously shown for other rhizosphere microorganisms (Barea et al. 1998). However, the stimulatory effects by $P$. fluorescens on AM fungi root colonisation was not noticed in the present study, since no difference in maize mycorrhizal colonisation was observed.

Maize has a high demand for $\mathrm{N}$ and $\mathrm{P}$ and their soil concentrations can affect AM fungal development. In fact, AM fungal colonisation is often negatively correlated with soil P values (Gianinazzi and Schüepp 1994; Liu et al. 2000). However, the results showed no significant difference in AM fungal colonisation between the treatments under different fertilisation regimes. $\mathrm{P}$ is critical for maximising plant growth and crop yields, playing a key role in several plant functions and making up to about $0.2 \%$ of the dry weight (Smith et al. 2011). Consequently, its absence or low amounts have negative consequences for plant development. The $80 \%$ decrease of $\mathrm{P}$ instead of $20 \%$ of the remaining nutrients, in the treatment of reduced fertilisation (F1), might contributed to hamper maize growth. Both AM fungi and PGPR are extensively recognised for their role in agriculture as biofertilisers (Vessey 2003; Nadeem et al. 2014). Nonetheless, the application of plant growth promoting microorganisms (PGPM) may not always contribute to plant growth, having other beneficial effects on plants such as nutritional enhancement (Ryan and Graham 2002). Even so, increases in plant nutrient concentration may not always translate into enhanced growth and yield (Miller 2000; Galvez et al. 2001). In this study no enhancement of biomass on plants inoculated with beneficial microbes was observed, being plant growth mainly dictated by the fertilisation regime. Although, no significant improvement in plant growth was observed, there was a noteworthy augmentation on nutrient shoot content by microbial inoculation including in the reduced (F1) or no fertilisation (F0) regimes. Plants require both macro and micronutrients which are generally obtained from the soil (White and Brown 2010). AM fungal roots can greatly enhance acquisition of mineral nutrients in host plants, especially those that are of low mobility or sparingly soluble (Clark and Zeto 2000). The N, P, K, Mg and Zn content on maize were positively affected by inoculation with $R$. irregularis, particularly in treatments where fertilisation was reduced or absent. The uptake of micronutrients by mycorrhizal plants is considered to be negatively influenced by the availability of $\mathrm{P}$ in the soil, which might explain the effect of mycorrhizal plants on $\mathrm{Zn}$ content (Lambert et al. 1979; Liu et al. 2000). The significance of AM fungi inoculation might be highest at low nutrient availability, mainly P. In fact, even though no difference in mycorrhizal colonisation was observed, the efficiencies of AM fungi in increasing shoot nutrient concentrations varied according to the fertilisation regime. $\mathrm{N}$ shoot concentration was directly correlated with fertilisation, and this 
might be related with the high demand of $\mathrm{N}$ by maize plants (Schröder et al. 2000). On the other hand, plants with single $P$. fluorescens inoculation presented most of the nutritional increments when full fertilisation was applied. This might indicate that the beneficial properties of the bacteria are stimulated by the presence of higher levels of nutrients in the soil. These results supported the overall hypothesis that microbial inoculum can increase nutrient assimilation of plants and can be used for integrating nutrient management strategies (Alloush and Clark 2001; Wu et al. 2005; Adesemoye et al. 2008; Berta et al. 2014). This ability in enhancing the concentration of nutrients provides an added value to food plants, which currently should be taken in great consideration.

\section{Conclusions}

The exploitation of beneficial microbes as biofertilisers appears to be a natural route. Particularly in low agrochemical input systems, they can be responsible for maintaining long term soil fertility and sustainability by improving the uptake efficiency and availability of macro and micro nutrients to plants. Plants inoculated with AM fungi and PGPR via seed coating displayed enhanced shoot concentration of macro and micronutrients, under different fertilisation regimes. The increments of maize nutrient contents suggest that PGPM-based inoculants applied via seed coating can be used and should be further evaluated as component of integrated nutrient management strategies. To our knowledge this is the first report on successful coating of maize seeds with inocula of AM fungi and PGPR. Seed coating for AM fungi inoculation had the same efficiency as direct soil inoculation, showing that there is great potential for PGPM inoculation in large scale agriculture, as it can allow the use of minor amounts of inocula and a more precise application. Thus, seed coating can open the way for large scale inoculation of beneficial microorganisms in maize production. Additionally, field experiments with maize and other crops will be useful to verify the efficacy of seed coating as a microbial delivery system and the benefits of the application.

\section{Acknowledgments}

We thank Banco Português de Germoplasma Vegetal, Instituto Nacional de Investigação Agrária e Veterinária for providing the seeds.

\section{Funding}

R.S. Oliveira, Y. Ma and I. Rocha acknowledge the support of Fundação para a Ciência e a Tecnologia (FCT) through the research grants SFRH/BPD/85008/2012, SFRH/BPD/76028/2011 and SFRH/BD/100484/2014, Fundo Social Europeu (FSE) and Programa Operacional do Capital Humano $(\mathrm{POCH})$. This work was financed by national funds through FCT under the Project EXPL/AGR-TEC/1204/2013 and by Fundo Europeu de Desenvolvimento Regional (FEDER), Eixo I do Programa Operacional Fatores de Competitividade (POFC) of Quadro de Referência Estratégica Nacional (QREN) (COMPETE: FCOMP01-0124-FEDER-041572). This work was also financed by FCT/MEC through national funds and the co-funding by the FEDER, within the PT2020 Partnership Agreement and COMPETE 2020, within the project UID/BIA/04004/2013. 


\section{References}

Adee SR, Pfender WF, Hartnet DC. 1990. Competition between Pyrenophora tritici-repentis and Septoria nodorum in the wheat leaf as measured with de Wit replacement series. Phytopathology. 80:1177-1182.

Adesemoye AO, Torbert HA, Kloepper JW. 2008. Enhanced plant nutrient use efficiency with PGPR and AMF in an integrated nutrient management system. Can J Microbiol. 54:876-886.

Adesemoye AO, Torbert HA, Kloepper JW. 2009. Plant growth-promoting rhizobacteria allow reduced application rates of chemical fertilizers. Microb Ecol. 58:921-929.

Alloush GA, Clark RB. 2001. Maize response to phosphate rock and arbuscular mycorrhizal fungi in acidic soil. Commun Soil Sci Plant Anal. 32:231-254.

Barea JM, Andrade G, Bianciotto VV, Dowling D, Lohrke S, Bonfante P, O'Gara F, Azcon-Aguilar C. 1998. Impact on arbuscular mycorrhiza formation of Pseudomonas strains used as inoculants for biocontrol of soil-borne fungal plant pathogens. Appl Environ Microbiol. 64:2304-2307.

Berta G, Copetta A, Gamalero E, Bona E, Cesaro P, Scarafoni A, D’Agostino G. 2014. Maize development and grain quality are differentially affected by mycorrhizal fungi and a growth-promoting pseudomonad in the field. Mycorrhiza. 24:161-170.

Bhardwaj D, Ansari M, Sahoo R, Tuteja N. 2014. Biofertilizers function as key player in sustainable agriculture by improving soil fertility, plant tolerance and crop productivity. Microb Cell Fact. 13:66.

Bhattacharyya PN, Jha DK. 2012. Plant growth-promoting rhizobacteria (PGPR): emergence in agriculture. World J Microbiol Biotechnol. 28:1327-1350.

Clark RB, Zeto SK. 2000. Mineral acquisition by arbuscular mycorrhizal plants. J Plant Nutr. 23:867-902.

Colla G, Rouphael Y, Bonini P, Cardarelli M. 2015. Coating seeds with endophytic fungi enhances growth, nutrient uptake, yield and grain quality of winter wheat. Int J Plant Prod. 9:171-190.

Couillerot O, Bouffaud ML, Muller D, Caballero-Mellado J, Moënne-Loccoz Y. 2010. Development of a real-time PCR method to quantify the PGPR strain Azospirillum lipoferum CRT1 on maize seedlings. Soil Biol Biochem. 42:2298-2305.

Couillerot O, Ramírez-Trujillo A, Walker V, von Felten A, Jansa J, Maurhofer M, Défago G, Prigent-Combarte C, Comte G, Caballero-Mellado J, et al. 2013. Comparison of prominent Azospirillum strains in Azospirillum-Pseudomonas-Glomus consortia for promotion of maize growth. Appl Microbiol Biotechnol. 97:4639-4649.

Ehsanfar S, Modarres-Sanavy SA. 2004. Crop protection by seed coating. Commun Agric Appl Biol Sci. 70:225-229.

EN 13805. 2014. Foodstuffs - determination of trace elements - pressure digestion. Brussels (Belgium): European Committee for Standardization.

Farrar K, Bryant D, Cope-Selby N. 2014. Understanding and engineering beneficial plant-microbe interactions: plant growth promotion in energy crops. Plant Biotechnol J. 12:1193-1206.

Fenton AM, Stephens PM, Crowley J, O'Callaghan M, O'Gara F. 1992. Exploitation of gene (s) involved in 2,4-diacetylphloroglucinol biosynthesis to confer a new biocontrol capability to a Pseudomonas strain. Appl Environ Microbiol. 58:38733878.

Galvez L, Douds Jr. DD, Drinkwater LE, Wagoner P. 2001. Effect of tillage and farming system upon VAM fungus populations and mycorrhizas and nutrient uptake of maize. Plant Soil. 228:299-308.

Garbaye J. 1994. Helper bacteria: a new dimension to the mycorrhizal symbiosis. New Phytol. 128:197-210.

Gianinazzi S, Schüepp H. 1994. Impact of Arbuscular mycorrhizas on substainable agriculture and natural ecosystems. Basel (Switzerland): Birkhäuser.

Giovannetti M, Mosse B. 1980. An evaluation of techniques for measuring vesicular arbuscular mycorrhizal infection in roots. New Phytol. 84:489-500.

Haas D, Défago G. 2005. Biological control of soil-borne pathogens by fluorescent pseudomonads. Nat Rev Microbiol. 3:307331.

Jarak M, Mrkovački N, Bjelić D, Jošić D, Hajnal-Jafari T, Stamenov D. 2012. Effects of plant growth promoting rhizobacteria on maize in greenhouse and field trial. Afr J Microbiol Res. 6:5683-5690.

Krey T, Vassilev N, Baum C, Eichler-Löbermann B. 2013. Effects of long-term phosphorus application and plant-growth promoting rhizobacteria on maize phosphorus nutrition under field conditions. Eur J Soil Biol. 55:124-130.

Kumar B, Trivedi P, Pandey A. 2007. Pseudomonas corrugata, A suitable bacterial inoculant for maize grown under rainfed conditions of Himalayan region. Soil Biol Biochem. 39:3093-3100.

Lambert DH, Baker DE, Cole H. 1979. The role of mycorrhizae in the interactions of phosphorus with zinc, copper, and other elements. Soil Sci Soc Am J. 43:976-980.

Landa BB, Mavrodi DM, Thomashow LS, Weller DM. 2003. Interactions between strains of 2,4-diacetylphloroglucinolproducing Pseudomonas fluorescens in the rhizosphere of wheat. Phytopathology. 93:982-994.

Liu A, Hamel C, Hamilton RI, Smith DL. 2000. Mycorrhizae formation and nutrient uptake of new corn (Zea mays L.) hybrids with extreme canopy and leaf architecture as influenced by soil N and P levels. Plant Soil. 221:157-166.

Mäder P, Kaiser F, Adholeya A, Singh R, Uppal HS, Sharma AK, Srivastava R, Sahadi V, Aragno M. 2011. Inoculation of root microorganisms for sustainable wheat-rice and wheat-black gram rotations in India. Soil Biol Biochem. 43:609-619.

Malusá E, Pinzari F, Canfora L. 2016. Efficacy of biofertilizers: challenges to improve crop production. In: Singh D, Singh $\mathrm{H}$, Prabha $\mathrm{R}$, editors.Microbial inoculants in sustainable agricultural productivity. India: Springer.

Malusá E, Sas-Paszt L, Ciesielska J. 2012. Technologies for beneficial microorganisms inocula used as biofertilizers. Sci 
World J. 2012:491206.

Miller MH. 2000. Arbuscular mycorrhizae and the phosphorus nutrition of maize: a review of Guelph studies. Can J Plant Sci. 80:47-52.

Nadeem SM, Ahmad M, Zahir ZA, Javaid A, Ashraf M. 2014. The role of mycorrhizae and plant growth promoting rhizobacteria (PGPR) in improving crop productivity under stressful environments. Biotechnol Adv. 32:429-448.

Njeru E, Avio L, Bocci G, Sbrana C, Turrini A, Bàrberi P, Oehl F. 2015. Contrasting effects of cover crops on "hot spot" arbuscular mycorrhizal fungal communities in organic tomato. Biol Fertil Soils. 51:151-166.

Oliveira RS, Carvalho P, Marques G, Ferreira L, Nunes M, Rocha I, Ma Y, Carvalho MF, Vosátka M, Freitas H. 2017 a. Increased protein content of chickpea (Cicer arietinum L.) inoculated with arbuscular mycorrhizal fungi and nitrogen-fixing bacteria under water deficit conditions. J Sci Food Agric. 97:4379-4385.

Oliveira RS, Carvalho P, Marques G, Ferreira L, Pereira S, Nunes M, Rocha I, Ma Y, Carvalho MF, Vosátka M, et al. $2017 \mathrm{~b}$. Improved grain yield of cowpea (Vigna unguiculata) under water deficit after inoculation with Bradyrhizobium elkanii and Rhizophagus irregularis. Crop Pasture Sci. 68:1052-1059.

Oliveira RS, Rocha I, Ma Y, Carvalho MF, Vosátka M, Freitas H. 2016a. Arbuscular mycorrhizal fungi are an alternative to the application of chemical fertilizer in the production of the medicinal and aromatic plant Coriandrum sativum L. J Toxicol Environ Health A. 79:320-328.

Oliveira RS, Rocha I, Ma Y, Vosátka M, Freitas H. 2016b. Seed coating with arbuscular mycorrhizal fungi as an ecotechnological approach for sustainable agricultural production of common wheat (Triticum aestivum L.). J Toxicol Environ Health A. 79:329-337.

Oliveira RS, Vosátka M, Dodd JC, Castro PML. 2005. Studies on the diversity of arbuscular mycorrhizal fungi and the efficacy of two native isolates in a highly alkaline anthropogenic sediment. Mycorrhiza. 16:23-31.

Pedrini S, Merritt DJ, Stevens J, Dixon K. 2016. Seed coating: science or marketing spin? Trends Plant Sci. 22:106-116.

Phillips JM, Hayman DS. 1970. Improved procedures for clearing and staining parasitic and vesicular-arbuscular mycorrhizal fungi for rapid assessment of infection. Trans Br Mycol Soc. 55:158-161.

Porter W. 1979. The "most probable number" method for enumerating infective propagules of vesicular arbuscular mycorrhizal fungi in soil. Aust J Soil Res. 17:515-519.

Rosas SB, Avanzini G, Carlier E, Pasluosta C, Pastor N, Rovera M. 2009. Root colonization and growth promotion of wheat and maize by Pseudomonas aurantiaca SR1. Soil Biol Biochem. 41:1802-1806.

Ryan MH, Graham JH. 2002. Is there a role for arbuscular mycorrhizal fungi in production agriculture? Plant Soil. 244: 263-271.

Sangeetha J, King Solomon E, Natarajan K, Rajeshkannan V. 2013. Efficacy of AMF and PGPR inoculants on maize (Zea mays L.) plant growth and their rhizosphere soil properties. In: Velu RK, editor. Microbiological research in agroecosystem management. India: Springer; p. 155-173.

Schröder JJ, Neeteson JJ, Oenema O, Struik PC. 2000. Does the crop or the soil indicate how to save nitrogen in maize production?: reviewing the state of the art. Field Crops Res. 66:151-164.

Scott JM, Hill CB, Jessop RS. 1991. Growth chamber study of phosphorus applied as drilled granules or as seed coatings to wheat sown in soils differing in P-sorption capacity. Fert Res. 29:281-287.

Smith SE, Jakobsen I, Grønlund M, Smith FA. 2011. Roles of arbuscular mycorrhizas in plant phosphorus nutrition: interactions between pathways of phosphorus uptake in arbuscular mycorrhizal roots have important implications for understanding and manipulating plant phosphorus acquisition. Plant Physiol. 156:1050-1057.

Taiz L, Zeiger E. 2002. Plant physiology. 3nd ed. Sunderland: Sinauer Associates Publishers.

Tang W, Pasternak JJ, Glick BR. 1995. Persistence in soil of the plant growth promoting rhizobacterium Pseudomonas putida GR12-2 and genetically manipulated derived strains. Can J Microbiol. 41:445-451.

Trouvelot A, Kough JL, Gianinazzi-Pearson V. 1986. Mesure du taux de mycorhization VA d'un systeme radiculaire. Recherche de methodes d'estimation ayant une signification fonctionnelle. In: Gianinazzi- Pearson V, Gianinazzi S, editors. Physiological and genetical aspects of mycorrhizae. France: INRA Press; p. 217-221.

Vessey JK. 2003. Plant growth promoting rhizobacteria as biofertilizers. Plant Soil. 255:571-586.

Von Felten A, Défago G, Maurhofer M. 2010. Quantification of Pseudomonas fluorescens strains F113, CHA0 and Pf153 in the rhizosphere of maize by strain-specific real-time PCR unaffected by the variability of DNA extraction efficiency. J Microbiol Methods. 81:108-115.

Vosátka M, Látr A, Gianinazzi S, Albrechtová J. 2012. Development of arbuscular mycorrhizal biotechnology and industry: current achievements and bottlenecks. Symbiosis. 58:29-37.

Walker V, Couillerot O, Von Felten A, Bellvert F, Jansa J, Maurhofer M, Comte G. 2011. Variation of secondary metabolite levels in maize seedling roots induced by inoculation with Azospirillum, Pseudomonas and Glomus consortium under field conditions. Plant Soil. 356:151-163.

Weller DM. 1983. Colonization of wheat roots by a fluorescent pseudomonad suppressive to take-all. Phytopathology. 73:1548-1553.

White PJ, Brown PH. 2010. Plant nutrition for sustainable development and global health. Ann Bot. 105:1073-1080.

Wu C, Cao H, Li G, Cheung C, Wong H. 2005. Effects of biofertilizer containing N-fixer, $P$ and $K$ solubilizers and AM fungi on maize growth: a greenhouse trial. Geoderma. 125:155-166.

Zerbe P. 2015. Small molecules with big impact: terpenoid phytoalexins as key factors in maize stress tolerance. Plant Cell Environ. 38:2139-2219. 